\title{
CARACTERÍSTICAS ECONÔMICO-FINANCEIRAS E A INTENSIDADE NO RECONHECIMENTO DE ATIVOS INTANGÍVEIS: EVIDÊNCIAS EM EMPRESAS BRASILEIRAS E AMERICANAS
}

\section{ECONOMIC AND FINANCIAL CHARACTERISTICS AND INTENSITY IN THE RECOGNITION OF INTANGIBLE ASSETS: EVIDENCES ON BRAZILIAN AND AMERICAN COMPANIES}

0 artigo foi aprovado e apresentado no IX Congresso da Associação Nacional de Programas de Pós-Graduação em Ciências Contábeis (ANPCONT), realizado de 31/5 a $3 / 6$ de 2015, em Curitiba - PR.

\begin{abstract}
RESUMO
Foram investigadas características econômico-financeiras que possam distinguir a intensidade no reconhecimento de ativos intangiveis (AIs) por empresas brasileiras e americanas. Por meio de um estudo empírico-analítico, com abordagem quantitativa, empregou-se a regressão logística, cuja variável dependente (dummy) foi constituída entre empresas com maior (1) ou menor (0) representatividade de AIs (1) em relação aos ativos totais. Foram analisadas 459 empresas (211 brasileiras e 248 americanas), no período entre o primeiro trimestre de 2010 e o último de 2014. Os resultados propõem que a influência do porte na intensidade no reconhecimento de AIs decorre de operações inerentes às grandes empresas, tais como o goodwill decorrente de combinação de negócios, registro de patentes e maior capacidade de investimento em P\&D. As empresas americanas tendem a possuir maior representatividade de AIs possivelmente pela facilidade de registro de marcas e patentes, além do fato de serem preponderantes dentre as intensivas no reconhecimento de AIs da amostra.
\end{abstract}

Palavras-chave: Ativos Intangiveis; Reconhecimento; Características Econômico-Financeiras.

\begin{abstract}
An investigation was conducted of the economic and financial characteristics that distinguish the intensity with which Brazilian and American companies recognize intangible assets (IA). Logistic regression was applied through an empirical and analytical study and quantitative approach with its dummy variable constituted between companies with higher (1) or lower (0) representativeness of IA (1) considering the total assets. In the period between the first quarter of 2010 and the last quarter of 2014, 459 companies were analyzed; 211 Brazilian and 248 American. Results suggest that the influence of size in the recognition of IA arises from operations inherent in large companies; for instance, the goodwill acquired in the business combination, patent registration and increased R\&D investment capacity. US firms tend to have a greater representativeness of IA, possibly due the ease of patents and trademarks registration, in addition to the fact that they are preponderant among the recognition of IAs of the sample.
\end{abstract}

Keywords: Intangible Assets; Recognition; Economic and Financial Characteristics.
Gleferson Rodrigo Lima da Silva

Graduado em Ciências Contábeis pela Universidade Federal Rural do Semi-Árido (Ufersa). Contato: Av. Francisco Mota, 572, Costa e Silva, Mossoró, RN, CEP: 59.625-900. E-mail: glefersonrodrigo@hotmail.com

\section{Wigno Christian de Oliveira Souza} Graduado em Ciências Contábeis pela Universidade Federal Rural do Semi-Árido (Ufersa). Contato: Av. Francisco Mota, 572, Costa e Silva, Mossoró, RN, CEP: 59.625-900. E-mail: wignochristian@hotmail.com

\section{Kléber Formiga Miranda}

Doutorando em Ciências Contábeis pela Universidade Federal da Paraíba (UFPB). Mestre em Administração pela Universidade Federal do Ceará (UFC). Especialista em Auditoria Contábil e graduado em Ciências Contábeis pela Universidade do Estado do Rio Grande do Norte (UERN). Docente do curso de Ciências Contábeis na Universidade Federal Rural do Semi-Árido (Ufersa). Contato: Av. Francisco Mota, 572, Costa e Silva, Mossoró, RN, CEP: 59.625-900. E-mail: mirandakf@ufersa.edu.br

\footnotetext{
Augusto Cezar da Cunha e Silva Filho Doutorando em Ciências Contábeis pela Universidade Federal da Paraíba (UFPB). Mestre em Ciências Contábeis pelo Programa Multi-institucional e Inter-regional da UnB, UFPB e UFRN. Graduado em Ciências Contábeis pela Universidade Federal da Paraíba (UFPB) Docente do curso de Ciências Contábeis na Universidade Federal Rural do Semi-Árido (Ufersa). Contato: Av. Francisco Mota, 572, Costa e Silva, Mossoró, RN, CEP: 59.625-900. E-mail: augusto.filho@ufersa.edu.br
} 


\section{INTRODUÇÃO}

O reconhecimento de um ativo intangível no balanço patrimonial das empresas só é possível quando for provável a geração de benefício econômico para a entidade por meio desse ativo e seu custo puder ser mensurado de forma confiável (CPC04 (R1), 2010). O fato de o intangível ser identificável, mas não possuir substância física dificulta seu processo de reconhecimento, como relatam Pucci et al. (2014). Algumas empresas, portanto, podem ter maior propensão em reconhecer esses ativos em relação a outras considerando características intrínsecas ao negócio.

As empresas possuem diversos mecanismos para torná-las diferentes e competitivas comparadas às suas concorrentes. A vantagem competitiva sustentável, constituída por meio de recursos e capacidades inerentes à produção heterogênea entre as empresas (BARNEY, 1991), depende de fatores diversos como presença de liderança (COCKBURN; HENDERSON; STERN, 2000), nome da marca, capital humano e estrutura organizacional (CORRADO; HULTEN; SICHEL, 2005), inovação (SCHUMPETER, 1988), capital intelectual (COCKBURN; GRILICHES, 1987) ou absorção de conhecimentos e operacionalização de mudanças (COHEN; LEVINTHAL, 1989).

Nessa amplitude de portfólios gerenciais, Teece (2015) estabelece a emergência do desenvolvimento de novos conceitos para análises de negócios, sendo os ativos intangíveis (AIs) uma métrica importante para refletir o valor existente na firma. Contudo, alguns ativos intangíveis, por não serem mensuráveis de modo confiável, não são reconhecidos integralmente pela contabilidade, distanciando o valor justo e o valor contábil (PUCCI et al., 2014).

O tratamento dispensado ao reconhecimento dos AIs é orientado pelo Comitê de Pronunciamentos Contábeis (CPC), no Brasil, e pelo Financial Accounting Standards Board (FASB), nos Estados Unidos. Embora apenas o padrão brasileiro possa convergir ao padrão internacional, adotado pelo International Accounting Standards Board (IASB), ambos se alinham quanto aos critérios para reconhecimento de AIs. Entretanto, empresas americanas possuem melhor acesso a registros de suas invenções, além de capacidade tecnológica superior (GOUVEIA, 2007; MONACO, 2014; CAVALCANTI; PEREIRA, 2014), podendo essas vantagens se refletirem na intensidade de reconhecimento de AIs.

Pesquisas nacionais e internacionais contribuíram investigando a relação entre características econômico-financeiras e os níveis de evidenciação de ativos intangíveis, tais como o tamanho/porte das empresas (SHAKINA; MOLODCHIK, 2014; ARRIGHETTI; LANDINI; LASAGNI, 2014; AVELINO; PINHEIRO; LAMOUNIER, 2012; SANDNER; BLOCK, 2011; MACAGNAN, 2009; GREENHALGH; ROGERS, 2006); endividamento (KAYO; TEH; BASSO, 2006; CHAN; LOKONISHOK; SOUGIANNIS (2001); HOLTHAUSEN; WATTS, 2001); rentabilidade (DECKER et al., 2013; MIRANDA; GALLON; NOGUEIRA, 2011; BOUJELBEN; FEDHILA, 2011; MARROCU et al., 2011; MACAGNAN, 2009; PEREZ; FAMÁ, 2006; KAYO; FAMÁ, 2004); receita líquida, patrimônio líquido e valor de mercado (RITTA; ENSSLIN, 2010); setor, grau de internacionalização, anos de existência e diferença entre o preço da ação (MACAGNAN, 2009), etc.

A presente pesquisa apresenta uma contribuição diferente, qual seja avaliar características econômico-financeiras (porte, endividamento, rentabilidade, intensidade tecnológica) como fatores capazes de influenciar as chances de uma empresa ser intensiva no reconhecimento de AIs, propondo um comparativo entre empresas brasileiras e americanas. Diante do exposto, surge a seguinte questão de pesquisa: Quais caracteristicas econômico-financeiras são significativas para influenciar a chance de uma empresa apresentar maior intensidade no reconhecimento de ativos intangiveis?

Entre as principais contribuições deste estudo destacam-se: a) identificar, no Brasil e nos Estados Unidos (e em conjunto), características econômico-financeiras influentes para a intensidade no reconhecimento de AIs; b) investigar a intensidade no reconhecimento de AIs no Brasil após o processo de convergência das normas brasileiras às internacionais (IFRS); c) demonstrar aspectos das empresas intensivas no reconhecimento de AIs, cujos valores, provavelmente, são decorrentes de estratégias geradoras de vantagem competitiva. As características utilizadas nesta pesquisa levam em consideração o porte (valor de mercado), o endividamento (relação Passivo/PL), a rentabilidade (ROA), a intensidade tecnológica (o setor de atuação) e o mercado (bolsa brasileira ou americana).

\section{REFERENCIAL TEÓRICO 2.1 Ativos Intangíveis}

Nas economias atuais, o conceito de intangíveis tornou-se fundamental, especialmente pela importância dada por terceiros à avaliação desses ativos. Os intangíveis (inclusive o ágio por expectativa de rentabilidade futura - goodwill) constituem o acréscimo de valor obtido por uma empresa por meio de aspectos endógenos e individuais. Porém, mesmo com essa crescente importância em mensurar e reconhecer ativos constitutivos da vantagem competitiva em um ambiente complexo, a contabilidade falha no reconhecimento de alguns intangiveis, especialmente pela descaracterização de "identificabilidade" ou "controle" (PUCCI et al., 2014).

Lev (2001) associa o interesse em ativos intangíveis à competição e ao desenvolvimento de tecnologia da informação, elevando os ativos intangíveis (AIs) ao nível gerador de valor nas empresas. Assim, AIs sugerem perspectiva de resultados futuros, característica essencial para um ativo, conforme constatado por Sorescu e Spanjol (2008) e Nisiyama e Oyadomari (2012).

Para Perez e Famá (2006), AIs, como marcas, patentes, concessões públicas, capital intelectual e goodwill, são ativos singulares, cujas características únicas poderiam possibilitar a diferenciação entre as empresas e a obtenção de vantagens competitivas. Na mesma linha, Ritta, Ensslin e Ronchi (2010) apontaram os AIs combinados com outros fatores, tais 
como localização geográfica, habilidades gerenciais e aspectos comerciais, como vantagens na geração de resultados e um diferencial competitivo no mercado.

Os investimentos em Pesquisa e Desenvolvimento (P\&D), goodwill, concessões e marcas e patentes são as referências mais próximas percebidas nos intangíveis, seja em pesquisas acadêmicas ou nas demonstrações contábeis. Segundo Crisóstomo (2009), os sistemas contábeis fazem referência a três categorias de intangíveis: goodwill, P\&D e outros ativos intangíveis, esses últimos constituídos, por exemplo, pelas patentes, marcas, direitos de autoria, quotas de importação e licenças. Ainda assim, Pucci et al. (2014) revelam haver o distanciamento entre os valores atribuídos pela contabilidade a esses ativos e a representação fidedigna com base no seu real valor, tornando a informação contábil reportada inadequada na perspectiva do investidor.

No Brasil, por exemplo, o CPC 04 (R1), emitido pelo Comitê de Pronunciamentos Contábeis (CPC), estabelece critérios para considerar um ativo como intangível. Os critérios são satisfeitos quando o ativo for separável, resultar de direitos contratuais e for controlado pela entidade (CPC 04 (R1), 2010). Dessa forma, apenas os intangíveis que atendam a esses critérios serão contabilmente reconhecidos. Embora se tenha identificado certo avanço no aumento das possibilidades de reconhecimento, os investimentos em P\&D, normalmente associados à vantagem competitiva, não são geralmente reconhecidos pela contabilidade, conforme relatam Beuren, Theiss e Sant'Ana (2013).

Em se tratando da definição de ativos intangiveis, os normativos dos padrões brasileiro (CPC 04), americano (ASC 350) e internacional (IFRS 38) são convergentes, assim como o tratamento para o goodwill e ativos gerados internamente. Geralmente, em casos com confiabilidade, como investimentos em desenvolvimento (pesquisas são classificadas como despesas), marcas e patentes e a aquisição de outras empresas (combinação de negócios), há o reconhecimento mais frequente de intangíveis (ERNST \& YOUNG, 2011).

Reina, Ensslin e Jorge (2010) destacam a habitualidade de se verificar empresas com bens intangíveis superiores aos bens tangiveis nos seus balanços patrimoniais. Destacam as marcas como os principais AIs para essas empresas, porém, pelo grau de subjetividade inerente, o seu reconhecimento é dificultado por não atender aos critérios exigidos pelos normativos contábeis. Gerencialmente, para Sánchez, Chaminade e Olea (2000), os ativos intangíveis passam por três etapas: a) identificação de intangíveis críticos relacionados à criação de valor; b) mensuração desses intangíveis e; c) monitoramento e controle dos AIs.

Ledoux e Cormier (2013) observaram melhorias no reconhecimento de intangíveis e despesas após a adoção do IAS 38 por empresas canadenses não-financeiras. Espera-se a mesma postura em empresas brasileiras. Contudo, o estudo também identificou a perda de relevância na evidenciação voluntária, especialmente em informações sobre inovação.

Diante do exposto, é razoável encontrar características divergentes entre empresas mais e menos intensivas no reconhecimento de ativos intangíveis, pois, considerando que tais ativos possibilitam a diferenciação entre as empresas e a obtenção de vantagens competitivas, apenas empresas com características específicas seriam capazes de conseguir reconhecer valores expressivos de AIs em suas demonstrações.

Algumas características econômico-financeiras são destacadas em pesquisas nacionais e internacionais quanto à sua relação com os niveis de evidenciação de AIs, como, por exemplo, porte (ARRIGHETTI; LANDINI; LASAGNI, 2014; AVELINO; PINHEIRO; LAMOUNIER, 2012; MACAGNAN, 2009; SHAKINA; MOLODCHIK, 2014); receita líquida, patrimônio líquido e valor de mercado (RITTA; ENSSLIN, 2010); setor, grau de internacionalização, anos de existência e diferença entre o preço da ação (MACAGNAN, 2009); endividamento (KAYO; TEH; BASSO, 2006; MACAGNAN, 2009; CHEN; JIANG; LIN, 2014); rentabilidade (KAYO; FAMÁ, 2004; PEREZ; FAMÁ, 2006; MACAGNAN, 2009; DECKER et al., 2013); consórcios de exportação (ANTOLDI; CERRATO; DEPPERU, 2013); e ambientes mais competitivos (fator contingencial) (MOURA; SCARPIN; MECKING, 2013). É importante salientar que tais pesquisas apresentaram resultados contraditórios quanto à propensão das empresas em possuir ativos intangíveis reconhecidos.

As características econômico-financeiras analisadas nessa pesquisa, como influentes para haver maior intensidade no reconhecimento de ativos intangíveis, são: porte, endividamento, intensidade tecnológica, rentabilidade e o mercado de atuação (brasileiro e americano), conforme hipóteses da pesquisa a seguir apresentadas com suas respectivas fundamentações.

\subsection{Formulação das Hipóteses}

Consonante com Arrighetti, Landini e Lasagni (2014), Avelino, Pinheiro e Lamounier (2012) e Macagnan (2009), a pesquisa avaliará a influência do porte na probabilidade de uma empresa possuir maior intensidade no reconhecimento de AIs nas suas demonstrações. As grandes empresas possuem maior número de contratos, projetos, atividades produtivas e comerciais e necessitam de mais financiamento (MACAGNAN, 2009). Adicionalmente, empresas com porte maior possuem melhor estrutura para manter a acumulação de AIs e protegê-los, absorvendo o custo de marcas e patentes (ARRIGHETTI; LANDINI; LASAGNI, 2014).

Shakina e Molodchik (2014) complementam reforçando a influência dos intangíveis na atratividade do investimento, especialmente quando as empresas possuem experiência, tamanho e foco inovador. O tamanho ou porte da firma será mensurado, nessa pesquisa, pelo valor de mercado em consonância com os trabalhos de Greenhalgh e Rogers (2006) e Sandner e Block (2011). Dessa forma, apresenta-se a primeira hipótese da pesquisa:

$\mathrm{H}_{1}$ : Empresas de grande porte possuem maior probabilidade de serem mais intensivas no reconhecimento de AIs nas suas demonstrações. 
O endividamento, verificado por Kayo, Teh e Basso (2006) e Macagnan (2009) como influente na evidenciação de AIs, também comporá a avaliação dessa pesquisa. Kayo, Teh e Basso (2006) identificaram menor endividamento em empresas intensivas em inovação, cujas proxies foram número de patentes e investimentos em P\&D. Em contrapartida, Macagnan (2009) aponta o endividamento como fonte de financiamento dos intangíveis, justificado pelo retorno futuro.

Entretanto, Holthausen e Watts (2001) destacam uma relação inversa entre AIs e contratos de dívida, na qual, em situação de liquidação, os AIs seriam presumivelmente iguais a zero. Holthausen e Watts (2001) acrescentam o fato de que, na análise para concessão de contratos de dívidas, os AIs são geralmente excluídos, pois constituem indicativo de risco. Essas afirmações se alinham aos achados de Chan, Lakonishok e Sougiannis (2001) ao evidenciarem uma relação entre os dispêndios com P\&D e a volatilidade dos retornos das ações, sugerindo maior risco (volatilidade) à medida que os dispêndios com P\&D se ampliam, impactando negativamente na percepção dos investidores quanto à capacidade desses investimentos gerarem futuros benefícios econômicos.

Dessa forma, em consonância com Watts (2003), considera-se a verificabilidade dos números como fator preponderante nas relações com contratos de dívida, propondo-se uma relação inversa entre os AIs e o endividamento das empresas. De fato, o passivo das empresas constitui os interesses dos usuários não acionistas, para os quais o risco contratual se reduz por meio de investimentos em ativos com maior poder de realização. De acordo com Holthausen e Watts (2001), a realização dos AIs é constituída por estimativa e, portanto, eles são pouco verificáveis. Assim, a segunda hipótese da pesquisa fica assim constituída:

$\mathrm{H}_{2}$ : Empresas mais endividadas possuem maior probabilidade de serem menos intensivas no reconhecimento de AIs nas suas demonstrações.

Campos e Ruiz (2009) advertem para a setorização das empresas quando se busca entender relações envolvendo aspectos inovativos, sugerindo a avaliação de setores com base na sua intensidade tecnológica, tais como a setorização proposta pelo Índice Brasil de Inovação (IBI), baseada na intensidade em P\&D. Dessa forma, a intensidade tecnológica pode implicar uma maior probabilidade de uma empresa ser intensiva no reconhecimento de AIs.

Pavitt (1984) apresenta uma taxonomia para inovação, considerando a diferença do seu uso por empresas industriais, dando base para a classificação setorial do Índice Brasil de Inovação (IBI), para a avaliação de setores intensivos em P\&D. Na mesma linha de artigos nacionais, serão considerados como itens de inovação, nesta pesquisa, os itens de AIs reconhecidos nas demonstrações contábeis. Axtle-Ortiz (2013) também confirma essa perspectiva incluindo o setor industrial entre os fatores influentes no valor dos ativos intangíveis.

Com base na intensidade tecnológica captada pela classificação setorial do IBI, propõe-se uma maior propensão de reconhecimento de AIs pelas empresas de setores intensivos em P\&D, haja vista a possibilidade de registro de marcas, patentes e outros intangíveis passíveis de contabilização. Ressalta-se, todavia, achados como os de Chan, Lakonishok e Sougiannis (2001), nos quais essa relação não é positiva, mas, sim, negativa. Portanto, considerando a propensão em reconhecer mais AIs nas demonstrações com base na intensidade tecnológica das empresas, formula-se a terceira hipótese da pesquisa:

$\mathrm{H}_{3}$ : Empresas com maior intensidade tecnológica possuem maior probabilidade de serem mais intensivas no reconhecimento de AIs nas suas demonstrações.

$\mathrm{Na}$ abordagem desta pesquisa, alinhada aos achados de Sorescu e Spanjol (2008), a inovação sugere uma perspectiva de resultados futuros e um aumento de valor das empresas. Sorescu e Spanjol (2008) ainda demonstram a busca das empresas por compensação com retornos anormais, dado o risco de inovação delas. A rentabilidade está associada à continuidade da empresa, logo, as inovações são fundamentais para a vantagem competitiva empresarial, conforme Nisiyama e Oyadomari (2012). Portanto, sendo os AIs recursos geralmente correspondentes aos registros decorrentes de atividades de inovação, espera-se uma relação positiva entre a sua intensidade e a rentabilidade.

A rentabilidade das empresas é incluída nas pesquisas como fator influente para uma maior intensidade de AIs. Essas pesquisas fundamentam o fato de que há melhor resultado quando empresas possuem maior reconhecimento de AIs. Embora Brito, Brito e Morganti (2009) não terem identificado uma relação significativa entre indicadores de inovação e métricas de lucratividade, outras pesquisas identificaram essa relação (DECKER et al., 2013; MIRANDA; GALLON; NOGUEIRA, 2011; MACAGNAN, 2009; PEREZ; FAMÁ, 2006; KAYO; FAMÁ, 2004). A divergência de resultados pode ser atribuída a problemas econométricos, de corte temporal, amostra, dentre outros fatores.

Os achados de Boujelben e Fedhila (2011) alinham-se aos demais ao demonstrar que há um efeito positivo do investimento em AIs no fluxo de caixa operacional futuro, persistindo em até três períodos de defasagem. Marrocu, Paci e Pontis (2011) sugerem a acumulação de AIs dada a sua relação positiva com a produtividade das empresas. Desse modo, propõe-se a quarta hipótese de pesquisa:

$\mathrm{H}_{4}$ : Empresas mais rentáveis possuem maior probabilidade de serem mais intensivas no reconhecimento de AIs nas suas demonstrações.

Para a quinta hipótese, abordou-se a diferença entre empresas americanas e brasileiras, sob a justificativa de haver empresas com maior intensidade de AIs nas empresas estadunidenses, pois a média de investimentos de P\&D brasileira é baixa em relação àquela de países desenvolvidos (CABRAL; TRAILL, 2003; CABRAL, 2007). Embora não se tenha identificado pesquisas voltadas diretamente à diferenciação específica entre esses mercados, é possível propô-la com base em Gouveia (2007), Monaco (2014) e Cavalcanti e Pereira (2014).

Todos (GOUVEIA, 2007; MONACO, 2014; CAVALCANTI; PEREIRA, 2014) assinalam pela ampla vantagem dos Estados Unidos sobre o Brasil quando se trata de registro de invenções e maior capacidade tecnológica. De acordo com 
Monaco (2014), no Brasil, além do baixo volume, o tempo de espera para registro de patentes passou de pouco mais de 6 anos, em 2003, para 11 anos, em 2013. Portanto, um retrocesso. Considerando o registro contábil de um ativo intangível com base na confiabilidade e controle, os ativos intangíveis de empresas brasileiras passam bastante tempo para absorver tais investimentos. Nessa perspectiva, a hipótese cinco propõe:

$\mathrm{H}_{5}$ : Empresas americanas possuem maior probabilidade de serem mais intensivas no reconhecimento de AIs nas suas demonstrações, comparadas a empresas brasileiras.

\section{METODOLOGIA}

Quanto à caracterização da pesquisa, optou-se por um estudo empírico-analítico, que, segundo Martins (2002, p.34), “[...] são abordagens que apresentam em comum a utilização de técnicas de coleta, tratamento e análise de dados marcadamente quantitativos [...]. Têm forte preocupação com a relação causal entre variáveis. A validação da prova científica é buscada através de testes dos instrumentos, graus de significância e sistematização das definições operacionais.”.

Considerando os dados necessários à execução desta pesquisa, utilizou-se o banco de dados do Economatica ${ }^{\circledR}$ como fonte de coleta. A população foi composta por todas as empresas ativas nessa base, listadas na Bolsa de Valores de São Paulo (BM\&FBOVESPA), na New York Stock Exchange (NYSE), na National Association Securities Dealers Automated Quotation (NASDAQ) ou na American Stock Exchange (AMEX), com dados trimestrais e dos demonstrativos consolidados do período de 2010 a 2014, compondo 20 períodos de análise. Esse período se deve ao fato de o Pronunciamento Técnico CPC 04 (R1) - Ativo Intangível - ter sido aprovado em 2010, no Brasil. Após a coleta, o número de empresas totalizou 1.616, sendo 380 brasileiras e 1.236 americanas.

Foram excluídas as empresas financeiras, devido às regulamentações e peculiaridades específicas do setor (KAYO; TEH; BASSO, 2006); as empresas que não tinham Ativos Intangíveis reconhecidos; e as que não apresentaram os demais dados necessários disponíveis suficientemente. Portanto, a amostra totalizou 746 empresas com 11.389 observações, dividida com base no mercado de atuação, sendo 280 empresas brasileiras (4.782 obs) e 466 americanas (6.607 obs). Considerando a intensidade de reconhecimento em AIs, 245 empresas (2.848 obs) ficaram abaixo do primeiro quartil e 219 empresas (2.847 obs) ficaram após o terceiro quartil, tendo 5 empresas sido classificadas nos dois quartis durante o período de análise, motivo pelo qual a totalização de empresas excede em cinco, mas o número de observações permanece inalterado. $\mathrm{O}$ enquadramento da intensidade dos AIs estabeleceu-se em observação à segregação da amostra em 4 partes iguais. Assim, o quartil inferior se refere aos 25\% das observações com menor valor de AI e o quartil superior aos $25 \%$ das observações com maior valor de AI.

Os dados necessários à execução desta pesquisa foram todos coletados no banco de dados do Economatica@, cujos valores foram analisados por meio da estatística descritiva, com a indicação das médias, desvios-padrão, máximos e mínimos. Para verificar a existência de diferenças estatisticamente significativas das variáveis utilizadas (porte, endividamento e rentabilidade) entre as empresas com mais e menos intensidade de AIs, utilizou-se o Teste $t$ de diferença de média para amostras independentes (GUJARATI; PORTER, 2011).

Em seguida, para verificar quais as variáveis indicam maior probabilidade de as empresas brasileiras e americanas terem mais intensidade no reconhecimento de AIs, utilizou-se a análise de regressão logística, conforme metodologia utilizada em estudos anteriores (ARRIGHETTI; LANDINI; LASAGNI, 2013; COSTA; SILVA; LAURENCEL, 2013). As análises foram feitas considerando isoladamente os mercados americano e brasileiro, bem como os dois mercados em conjunto com controle de efeito do mercado (brasileiro ou americano) por meio de dummy. $\mathrm{O}$ modelo empregado nesta pesquisa foi:

$$
\text { logit }(p)=\beta 0+\beta 1 * \text { porte }+\beta 2 * \text { endividamento }+\beta 3 * \text { rentabilidade }+\beta 4 * \text { bolsa }+\beta 5 * \text { int_tec }+\varepsilon
$$

A variável dependente (ativo intangível), calculada como o montante de ativos intangíveis dividido pelo ativo total, destaca-se como dicotômica (dummy). Atribuiu-se o valor 0 (zero) para empresas com menor intensidade de AIs e 1 (um) para empresas com maior intensidade de AIs. Como a menor e a maior intensidade de AIs se referem aos $25 \%$ inferior e superior da amostra, os demais quartis, isto é, $50 \%$ das observações, foram excluídos da análise. Consequentemente, as análises realizadas contaram com 5.695 observações, sendo 2.979 observações de 214 empresas brasileiras e 2.716 observações de 250 empresas americanas. A escolha do modelo logit é justificada pela opção metodológica de avaliar as intensidades extremas de AIs, caracterizada por utilizar uma dummy indicativa de maior (1) e menor (0) intensidade como variável dependente.

Como o constructo de hipóteses versa sobre a diferença entre os mercados brasileiro e americano, associada ao fato de ser realizado um controle das empresas por intensidade tecnológica, não foram controlados outros efeitos fixos decorrentes de possíveis heterogeneidades entre as empresas. Assim, os coeficientes foram estimados por meio de modelo logit com dados dispostos em pooled. As variáveis independentes, constituintes das características econômico-financeiras, contidas no modelo, suas definições (proxies) escolhidas e o sinal positivo ou negativo esperado para cada uma delas estão demonstrados no Quadro 1. 
Quadro 1 - Operacionalização das Variáveis Independentes (incentivos econômicos)

\begin{tabular}{|c|c|c|c|}
\hline Variável & Sigla & Definição & $\begin{array}{c}\text { Sinal } \\
\text { Esperado } \\
\text { Porte }\end{array}$ \\
Endividamento & Porte & Logaritmo natural do Valor de Mercado & + \\
Rentabilidade & Endiv & $\begin{array}{c}\text { Soma do Passivo Circulante com o Passivo Não Circulante } \\
\text { dividida pelo Patrimônio Líquido }\end{array}$ & + \\
Rent & Lucro Operacional dividido pelo Ativo Total & + \\
Bntensidade Tecnológica & Int_Tec & $\begin{array}{c}0 \text { (zero) para as empresas não intensivas tecnologicamente } \\
\text { e 1 (um) para as empresas intensivas tecnologicamente }\end{array}$ \\
\hline
\end{tabular}

Fonte: Elaborado pelos autores.

A classificação da intensidade tecnológica teve como parâmetro o ranking setorial da inovação do Índice Brasil de Inovação (IBI), o qual pressupõe a identificação de similaridades de comportamento tecnológico entre as empresas para qualificá-las como pertencentes a um mesmo grupo de intensidade tecnológica. O ranking considera 15 indicadores, equilibrando os esforços e os resultados das atividades tecnológicas das empresas. O Quadro 2 demonstra os setores analisados, separados conforme a intensidade tecnológica, sugerida pelo IBI. O código Classificação Nacional de Atividades Econômicas (CNAE) de cada uma das atividades, consideradas pelo IBI como intensivas em tecnologia, foi cruzado com as atividades de cada empresa de acordo com a classificação do Economatica ${ }^{\circledR}$. Considerando o alinhamento entre a proposta do IBI e da Organização para Cooperação e Desenvolvimento Econômico (OCDE) para ranquear empresas por intensidade tecnológica, é possível utilizar a mesma classificação para as empresas americanas.

Quadro 2 - Setores com e sem intensidade tecnológica, conforme IBI

\begin{tabular}{|ccc|}
\hline Com Intensidade Tecnológica & Sem Intensidade Tecnológica \\
Alimentos e Bebidas & Petróleo e Gás & Agro e Pesca \\
Eletroeletrônicos & Química & Comércio \\
Máquinas Industriais & Siderurgia e Metalurgia & Construção \\
Mineração & Software e Dados & Energia Elétrica \\
Minerais não Metálicos & Telecomunicações & Transporte e Serviços \\
Veículos e peças & Têxtil & \\
Papel e Celulose & & \\
\hline
\end{tabular}

Fonte: Dados da pesquisa.

Após calcular os coeficientes da regressão logística, avaliou-se a associação entre as variáveis independentes e a variável de resultado. Assim, realizou-se o teste de Wald, cuja finalidade é aferir o grau de significância de cada coeficiente da equação logística, inclusive a constante. Em sequência, foi feito o Log Likelihood Value (LR Statistic), a fim de avaliar a significância do modelo estimado para aferir a capacidade do modelo em estimar a probabilidade associada à ocorrência de determinado evento. Para mitigar a fragilidade da análise isolada do LR statistic, foram utilizados dois indicadores Pseudos-R², quais sejam, Cox; Snell e Nagelkerke.

Por fim, para verificar o nível de ajustamento do modelo, aplicaram-se dois testes: Hosmer e Lemeshow e Count $R^{2}$ para validação do ajuste do modelo (GUJARATI; PORTER, 2011; DIAS FILHO; CORRAR, 2009). A estatística Count R2 consiste no somatório do número de previsões corretas adotando a probabilidade de 0,5 como referência. Dessa forma, conforme a Tabela 1, observa-se que o modelo exposto realizou 5.695 (ALL), 2.979 (BR) e 2.716 (EUA) simulações, obtendo uma média de $89,78 \%$ (ALL), 88,86\% (BR) e 90,54\% (EUA) de acurácia do modelo, que são médias relativamente altas.

Tabela 1 - Teste Count R2 - Classificação dos Acertos do Modelo

\begin{tabular}{ccccc}
\hline \multicolumn{2}{c}{ Teste de Count R2 - Amostra Geral (ALL) } & & \\
\hline Classificado & $\mathbf{0}$ & $\mathbf{1}$ & Total \\
Mais Intensivas AIs & 2.621 & 356 & 2.977 \\
Menos Intensivas AIs & 226 & 2.492 & 2.718 \\
Total & Classificados Corretamente: 89.78\% & $\mathbf{2 . 8 4 8}$ & $\mathbf{5 . 6 9 5}$ \\
& & & \\
\hline
\end{tabular}




\begin{tabular}{|c|c|c|c|}
\hline \multicolumn{4}{|c|}{ Teste de Count R2 - Amostra Empresas Brasileiras (BR) } \\
\hline Classificado & 0 & 1 & Total \\
\hline Mais Intensivas AIs & 597 & 169 & 766 \\
\hline Menos Intensivas AIs & 163 & 2.050 & 2.213 \\
\hline Total & 2.874 & 2.848 & 2.979 \\
\hline \multicolumn{4}{|c|}{ Classificados Corretamente: $88.86 \%$} \\
\hline \multicolumn{4}{|c|}{ Teste de Count R2 - Amostra Empresas Americanas (EUA) } \\
\hline Classificado & 0 & 1 & Total \\
\hline Mais Intensivas AIs & 2.006 & 176 & 2.182 \\
\hline Menos Intensivas AIs & 81 & 453 & 534 \\
\hline Total & 2.087 & 629 & 2.716 \\
\hline \multicolumn{4}{|c|}{ Classificados Corretamente: $90.54 \%$} \\
\hline
\end{tabular}

Fonte: Dados da Pesquisa

O teste Hosmer e Lemeshow avalia a hipótese nula de inexistência de diferenças significativas entre os resultados previstos pelo modelo e os observados, indicando, assim, a precisão do modelo. Vale destacar que o modelo é considerado aderente se a probabilidade do teste for maior que 5\% (GUJARATI; PORTER, 2011; DIAS FILHO; CORRAR, 2009). Os testes para cada amostra analisada são apresentados na Tabela 2.

Tabela 2 - Teste de Hosmer e Lemeshow

\begin{tabular}{cc}
\hline Teste de Hosmer e Lemeshow - Amostra Geral (ALL) & Resultados \\
\hline Hosmer e Lemeshow & 5,27 \\
Estatística Qui-quadrado & 0,1534 \\
P-value & Resultados \\
\hline Teste de Hosmer e Lemeshow - Amostra Empresas Brasileiras (BR) & 5,24 \\
\hline Estatística Qui-quadrado & 0,1551 \\
\hline P-value & Resultados \\
\hline Heste de Hosmer e Lemeshow - Amostra Empresas Americanas (EUA) & 6,23 \\
\hline Estatística Qui-quadrado & 0,0445 \\
\hline P-value &
\end{tabular}

Analisando a Tabela 2, observam-se níveis de significância estatística de 15,34\% (ALL), 15,51\% (BR) e 4,45\% (EUA). Assim, o modelo é considerado aderente nas amostras ALL e BR, uma vez que o resultado acarreta a não rejeição da hipótese nula, ou seja, não existe diferença entre os valores previstos pelo modelo e os valores observados ao nível de significância de $1 \%$. Por outro lado, para a amostra EUA, o modelo perdeu poder de ajuste, mas considerando um nível de significância de $1 \%$, o modelo está bem ajustado. Dessa forma, os resultados discutidos neste artigo são validados conforme a capacidade de previsão definida pelos testes realizados.

\section{ANÁLISE DOS RESULTADOS}

Inicialmente, foram calculadas as estatísticas descritivas das variáveis da pesquisa para os grupos com maior (2.848 observações) e menor intensidade (2.847 observações) de AIs. Na Tabela 3, são apresentadas as estatísticas descritivas considerando toda a amostra analisada (ALL) e sua separação em mercado brasileiro (BR) e americano (US). 
Tabela 3 - Estatística descritiva

\begin{tabular}{ccccc}
\hline Variável & $\begin{array}{c}\text { Média } \\
\text { ALL } \\
\text { (BR/USA) }\end{array}$ & $\begin{array}{c}\text { Desvio Padrão } \\
\text { ALL } \\
\text { (BR/USA) }\end{array}$ & $\begin{array}{c}\text { Mínimo } \\
\text { ALL } \\
\text { (BR/USA) }\end{array}$ & $\begin{array}{c}\text { Máximo } \\
\text { ALL } \\
\text { (BR/USA) }\end{array}$ \\
\hline Porte_0 & 13.08 & 1.91 & 6.40 & 17.66 \\
Porte_1 & $(12.66 / 14.56)$ & $(1.86 / 1.19)$ & $(6.40 / 9.69)$ & $(17.66 / 17.10)$ \\
& 16.77 & 1.26 & 11.15 & 20.28 \\
Endivid_0 & $(16.20 / 16.97)$ & $(1.28 / 1.18)$ & $(11.14 / 13.89)$ & $(19.81 / 20.28)$ \\
& 1.94 & 37.28 & -271.05 & 1254.55 \\
Endivid_1 & $(2.78 / 2.54)$ & $(32.79 / 50.00)$ & $(-271.05 /-1.27)$ & $(992.25 / 1254.55)$ \\
& 0.46 & 41.23 & -2108.06 & 169.30 \\
Rentab_0 & $(2.65 / 0.331)$ & $(4.92 / 48.04)$ & $(0.044 /-2108.06)$ & $(73.22 / 169.30)$ \\
& 0.008 & 0.25 & -1.68 & 12.42 \\
Rentab_1 & $(-0.002 / 0.011)$ & $(0.28 / 0.03)$ & $(-1.68 /-0.33)$ & $(12.42 / 0.21)$ \\
\end{tabular}

Nota: 0 = "menor intensidade de AIs"; 1 = "maior intensidade de AIs".

Fonte: Dados da Pesquisa

Observa-se, em média, a presença de maior porte (tamanho), menor endividamento e maior rentabilidade entre as empresas com maior intensidade no reconhecimento de AIs em comparação com as demais. Conforme as hipóteses formuladas nesta pesquisa, esses resultados eram esperados.

Vale destacar, ainda, que, para todas as variáveis, a variação da média entre os grupos com mais e menos intensidade de AIs apresentou-se relativamente alta, indicando certa heterogeneidade no porte (variação de 28,15\%), endividamento (variação de $318,10 \%$ ) e rentabilidade (variação de $87,50 \%$ ). Da mesma forma, o desvio padrão das variáveis mostrou alta variação ao se comparar os grupos, o que é corroborado com a análise dos valores mínimos e máximos. Esse resultado indica alta dispersão dos dados em torno da média, o que pode ser considerado como esperado, visto que a amostra é composta por entidades de vários setores com estruturas patrimoniais diferentes e de empresas situadas em mercados diferentes, tornando a amostra heterogênea.

Para haver uma melhor compreensão das possíveis diferenças existentes entre os mercados brasileiro e americano, foram analisadas, isoladamente, as estatísticas descritivas por mercado. Assim, a Tabela 3 nos mostra que, em média, as empresas americanas com baixa e alta intensidade de Als são maiores em tamanho, menos endividadas e mais rentáveis em comparação às empresas brasileiras.

Para verificar diferenças de médias significativas entre as variáveis das empresas com maior e menor intensidade no reconhecimento de AIs, aplicou-se o Teste T de diferença de média para amostras independentes, conforme a Tabela 4. Essa técnica foi utilizada tanto na amostra total (ALL), como, também, de modo isolado nas amostras de cada mercado analisado (BR e EUA).

Tabela 4 - Resultados do Teste T de diferença de Média para Amostra Independente

\begin{tabular}{|c|c|c|c|}
\hline \multicolumn{4}{|c|}{ Painel A - Amostra Geral (ALL) } \\
\hline & Porte & Endividamento & Rentabilidade \\
\hline Estatística T & -85.902 & 2.175 & -2.990 \\
\hline p-valor & 0.000 & 0.029 & 0.002 \\
\hline \multicolumn{4}{|c|}{ Painel B - Amostra Empresas Brasileiras (BR) } \\
\hline & Porte & Endividamento & Rentabilidade \\
\hline Estatística T & -48.619 & 0.110 & -1.242 \\
\hline p-valor & 0.000 & 0.911 & 0.214 \\
\hline \multicolumn{4}{|c|}{ Painel C- Amostra Empresas Americanas (EUA) } \\
\hline & Porte & Endividamento & Rentabilidade \\
\hline Estatística T & -44.416 & 1.303 & -4.986 \\
\hline p-valor & 0.000 & 0.192 & 0.000 \\
\hline
\end{tabular}

Fonte: Dados da Pesquisa 
Observa-se, no Painel A, para a amostra geral (ALL), que a estatística do Teste T, para todas as variáveis, apresentou o p-valor inferior a 0,05, o que faz com que a hipótese nula seja rejeitada, ou seja, as empresas com maior e menor intensidade no reconhecimento de AIs possuem porte, endividamento e rentabilidade diferentes, estatisticamente. Tais evidências sustentam, de forma preliminar, que tais variáveis sejam fatores que influenciem a probabilidade de uma empresa apresentar alta ou baixa intensidade no reconhecimento de AIs em seus balanços patrimoniais.

Em contrapartida, os painéis B e C, referentes aos mercados brasileiro e americano, respectivamente, não apresentaram diferenças estatísticas nas médias de algumas das variáveis. As empresas brasileiras apresentam diferença estatística apenas na média do porte entre as empresas com maior e menor intensidade no reconhecimento de AIs, enquanto as americanas possuem médias do porte e da rentabilidade diferentes estatisticamente. Esses resultados sugerem não haver influência do endividamento das empresas brasileiras e americanas, assim como da rentabilidade das empresas brasileiras na probabilidade de uma empresa ser intensa ou não no reconhecimento de AIs. A aplicação da regressão logística permitiu verificar quais características econômico-financeiras são significativas para influenciar a intensidade no reconhecimento de AIs. Os resultados são apresentados na Tabela 5.

Tabela 5 - Estimativas dos Parâmetros e Significância de cada variável

\begin{tabular}{|c|c|c|c|}
\hline \multicolumn{4}{|c|}{ Painel A } \\
\hline Variável & Odds_ALL & Odds_BR & Odds_USA \\
\hline Porte & $7,205^{\star \star \star}$ & $5.746^{\star \star \star}$ & 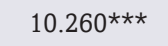 \\
\hline Endiv & 0.997 & $1.005^{\star \star}$ & 0.995 \\
\hline Rent & $7,07 \mathrm{e}-4^{\star \star \star *}$ & $3,70 \mathrm{e}-3^{\star \star \star}$ & $4.35 \mathrm{e}-9 * \star \star$ \\
\hline Int_Tecnol & $0.757^{\star \star}$ & 0.839 & $0.634^{\star \star}$ \\
\hline Bolsa & $1.583^{\star \star \star}$ & - & - \\
\hline \multicolumn{4}{|c|}{ Painel B } \\
\hline LR statistic & 5083.79 & 1954.70 & 1597.06 \\
\hline Prob. (LR) & 0.000 & 0.000 & 0.000 \\
\hline Cox-Snell R2 & 0.590 & 0.481 & 0.444 \\
\hline Nagelkerk R2 & 0.787 & 0.708 & 0.672 \\
\hline $\mathrm{N}^{\circ}$ Observ. & 5.695 & 2.979 & 2.716 \\
\hline
\end{tabular}

Nota 1: *Sig<0.05; ** Sig< $<0.01 ; * \star \star S i g<0.001$

Nota 2: Ausência de multicolinearidade [FIV(ALL):0,995, 0,996 e 0,998; FIV (BR): 0,275, 0,997 e 0,995; FIV(EUA): 0,358, 0,998 e 0,996 - todos para as variáveis PORT, ENDIV e RENT, respectivamente].

Fonte: Dados da Pesquisa

Verifica-se, no Painel B (Tabela 5), que as equações estimadas apresentaram significância estatística ao nível de 1\%, tendo em vista que o p-valor obtido pela estatística LR foi inferior a 0,01. Percebe-se, ainda, que o teste de Cox \& Snell indica que as variações ocorridas no log da razão de chance são explicadas pelo conjunto de variáveis em, aproximadamente, 59,6\%, 48,1\% e 44,4\%, para toda a amostra (ALL), mercado brasileiro (BR) e mercado americano (EUA), respectivamente. O Nagelkerke fornece resultados entre 0 e 1, indicando que o modelo é apto para explicar cerca de 78,7\% (ALL), $70,8 \%$ (BR) e $67,2 \%$ (EUA) das variações registradas na variável classificatória.

Conforme dito anteriormente, os modelos de regressão logística são geralmente analisados através dos odds ratio, ou seja, em termos da razão de chance de uma variável informar a mudança na chance de ocorrência do evento de interesse (GUJARATI; PORTER, 2011). Assim, ao analisar o odds ratio e a significância da variável PORTE (Tabela 3), conclui-se que, para todas as amostras analisadas (ALL, BR e USA), se a empresa possuir valor de mercado maior, maiores são suas chances de ser intensiva quanto ao reconhecimento de ativos intangíveis.

Esses achados corroboram a hipótese de que as maiores empresas são as que têm maior probabilidade de serem intensivas no reconhecimento de ativos intangíveis. Assim, de acordo com os resultados, o crescimento de uma empresa em valor implica o reconhecimento de AIs, possivelmente oriundos de combinações de negócios por aquisição de empresas menores, proteção de sua marca, investimento em novas tecnologias, dentre outros investimentos importantes para manutenção de sua vantagem competitiva. Os achados corroboram os trabalhos de Shakina e Molodchik (2014), Arrighetti, Landini e Lasagni (2014), Avelino, Pinheiro e Lamounier (2012), Sandner e Block (2011), Macagnan (2009) e Greenhalgh e Rogers (2006). 
Ainda de acordo com a Tabela 5, ao analisar o odds ratio e a significância da variável ENDIV, constata-se que, para as amostras ALL e USA, tal variável não apresentou significância estatística a 5\% (embora as empresas americanas tenham apresentado significância a 10\%). Esse resultado mostra não existir relação entre o endividamento e a intensidade no reconhecimento de AIs. Tais achados não eram esperados, principalmente porque os resultados da Tabela 3 evidenciam uma relação negativa forte entre o endividamento e a intensidade de AIs, para as amostras ALL e EUA. Portanto, não se pode afirmar, estatisticamente, que o fato de uma empresa americana ser intensiva ao reconhecimento de AIs acarretará dificuldade de acesso a capital de terceiros, dado o seu risco.

Por outro lado, considerando apenas as empresas brasileiras (BR), verifica-se que, se a empresa possuir um endividamento maior, a sua chance de ser intensiva quanto ao reconhecimento de ativos intangíveis é, em média, 0,5\% maior do que se o endividamento fosse menor. Esses achados não eram esperados, pois, apesar de a chance ser baixa, há indícios de que os credores não criam restrições de crédito quando uma empresa brasileira é intensiva em AIs. Esses achados contradizem os resultados das Tabelas 3 e 4, bem como a hipótese formulada e alguns trabalhos anteriores (KAYO; TEH; BASSO, 2006; CHAN; LAKONISHOK; SOUGIANNIS, 2001; HOLTHAUSEN; WATTS, 2001).

Ao analisar o odds ratio e a significância da rentabilidade (RENT), na Tabela 5, conclui-se que, para todas as amostras analisadas (ALL, BR e USA), se a empresa possuir alto retorno sobre o ativo, a sua chance de ser intensiva no reconhecimento de ativos intangíveis é menor do que se o retorno sobre o ativo fosse baixo, independentemente da amostra. Assim, a rentabilidade não aumenta a chance de as empresas apresentarem maiores valores de AIs.

Esses resultados vão de encontro com a hipótese teórica de que as empresas mais rentáveis são as que apresentam maior intensidade no reconhecimento de ativos intangíveis. Mesmo considerando o fato de a contabilidade não registrar todos os recursos intangíveis existentes, por motivos de restrição normativa, esperar-se-ia dos resultados uma relação positiva entre representatividade de AIs e rentabilidade, já que poderiam existir recursos ora não contabilizados influenciando positivamente os resultados da empresa. Contudo, sob outra ótica, o excesso de conservadorismo da informação contábil pode ocasionar maior reconhecimento de despesas em recursos possivelmente contabilizáveis como intangível, elevando a probabilidade de ocorrência de prejuízos. Outras pesquisas (DECKER et al., 2013; MIRANDA; GALLON; NOGUEIRA, 2011; MACAGNAN, 2009; PEREZ; FAMÁ, 2006; KAYO; FAMÁ, 2004) também identificaram uma relação positiva entre investimentos em AIs e rentabilidade. Os resultados inesperados alinharam-se aos achados de Brito, Brito e Morganti (2009) ao analisar empresas brasileiras e aos de Cho e Pucik (2005) analisando empresas americanas.

Da mesma forma, a variável intensidade tecnológica (INT_TEC) não apresentou relação consistente com o esperado, indo de encontro com a hipótese teórica de que as empresas com maior intensidade tecnológica são aquelas com maior intensidade no reconhecimento de ativos intangíveis. Conforme a análise do odds ratio, se a empresa possuir alta intensidade tecnológica, sua chance de ser intensiva quanto ao reconhecimento de ativos intangíveis é menor do que se a intensidade tecnológica fosse baixa. Tais achados corroboram os resultados de Chan, Lakonishok e Sougiannis (2001). Aqui também se estabelece uma possível limitação contábil, tendo em vista haver, nas empresas com maior intensidade tecnológica, maior propensão em intensidade nos investimentos em P\&D, cujo reconhecimento como AIs são restritivos (PAVITT, 1984).

O mercado de atuação da empresa (BOLSA) apresentou relação positiva e significativa, corroborando a hipótese de que as empresas que estão operando no mercado norte-americano possuem maior probabilidade de apresentarem maior intensidade no reconhecimento de ativos intangíveis. Um ponto que merece destaque é o fato de que se uma empresa estiver negociando suas ações no mercado norte-americano (em detrimento ao mercado brasileiro), aumenta-se 58,3\% sua chance de ser intensiva de AIs. Esse resultado, possivelmente, demonstra o baixo investimento em ativos intangíveis por empresas brasileiras, corroborando Gouveia (2007), Monaco (2014) e Cavalcanti e Pereira (2014), quanto à vantagem americana no que se refere à capacidade tecnológica e registro de invenções.

\section{CONCLUSÕES}

Esta pesquisa demonstra características econômico-financeiras significativas para influenciar a chance de uma empresa apresentar maior intensidade no reconhecimento de AIs. Para tal, partiu-se do pressuposto, teoricamente embasado, de haver divergência de intensidade de reconhecimento de AIs entre as empresas decorrentes do porte, endividamento, rentabilidade, intensidade tecnológica e mercado (brasileiro ou americano). O porte e o mercado de atuação da empresa se demonstram influentes na ampliação da intensidade de reconhecimento de AIs.

A análise da diferença de média das variáveis evidenciou que o porte, o endividamento e a rentabilidade são divergentes entre as empresas com maior intensidade no reconhecimento de AIs em comparação às demais, indicando divergência entre as características analisadas nesta pesquisa. Contudo, entre as empresas brasileiras, apenas o porte foi divergente entre os grupos, enquanto, nas empresas americanas, o porte e a rentabilidade foram diferentes. Esse achado foi importante por corroborar a perspectiva de que algumas características são capazes de indicar a probabilidade de maior reconhecimento de AIs.

O emprego da regressão logística possibilitou verificar quais as variáveis indicam maior probabilidade de as empresas brasileiras e americanas terem mais intensidade no reconhecimento de AIs. Destacou-se o mercado, com a revelação de uma maior probabilidade de empresas americanas e empresas de maior porte reconhecerem AIs.

O porte das empresas, independentemente do mercado de atuação (brasileiro ou americano), apresentou maior probabilidade de tornar as empresas intensivas em AIs, o que pode ser explicado pelo fato de as empresas terem mais condi- 
ções econômicas e financeiras de possuírem AIs identificáveis e com reconhecimento permitido pelas normas contábeis, tais como o registro de patentes, marcas, e, especialmente, o goodwill decorrente de combinações de negócios. A maior propensão de empresas do mercado americano serem intensivas em AIs pode ter se beneficiado desse aspecto da amostra, pois as maiores empresas e as mais intensivas em AIs estão nesse mercado, além do fato de empresas americanas terem o registro de patente mais facilitado. Dessa forma, não se rejeitam as hipóteses 1 (porte) e 5 (mercado) da pesquisa.

A rentabilidade e a intensidade tecnológica tiveram suas hipóteses rejeitadas $\left(\mathrm{H}_{3}\right.$ e $\left.\mathrm{H}_{4}\right)$, dado o fato de apresentarem menor probabilidade de tornarem as empresas intensivas em AIs. Não foram identificadas evidências capazes de explicar a rejeição dessas hipóteses, todavia, alerta-se para a possibilidade de os resultados decorrerem das restrições normativas para reconhecimento de alguns AIs. Embora não tenham sido objeto desta pesquisa e não haja evidências empíricas que sustentem qualquer afirmação sobre essa divergência, é razoável esperar que empresas rentáveis e intensivas em tecnologia possuam uma maior representatividade de AIs.

A Hipótese 2 também foi rejeitada, pois o endividamento foi significativo apenas no mercado brasileiro e com sinal divergente do proposto. A propensão de empresas utilizarem capital de terceiros para financiar seus AIs não foi verificada no mercado americano. No mercado brasileiro, há uma maior chance, embora com baixo percentual, de as empresas serem mais intensivas em AIs com financiamento de capital de terceiros. O fato de o endividamento ter considerado toda a dívida (onerosa e não onerosa) pode ter implicado esses resultados, contudo, a base de consulta não dispunha desses valores individualizados para as empresas americanas.

Dos resultados, depreendem-se algumas implicações práticas. Destaca-se a fragilidade de empresas brasileiras de menor porte serem mais intensivas no reconhecimento de AIs, pois, conforme os resultados, as empresas americanas de grande porte atuantes em mercado desenvolvido e, portanto, mais competitivo, tendem a apresentar uma maior intensidade no reconhecimento desses ativos. As evidências aqui apresentadas se limitam à amostra estudada, ao período e à metodologia empregada. Sendo assim, outras pesquisas podem ser realizadas com ampliação do corte temporal, utilização de outras proxies para as variáveis e/ou inclusão de novas variáveis e investigação em outros mercados.

\section{REFERÊNCIAS}

ANTOLDI, F.; CERRATO, D.; DEPPERU, D. SMEs export consortia and the development of intangible resources. Journal of Small Business and Enterprise Development, v. 20, n. 3, p. 567-583, 2013.

ARRIGHETTI, A.; LANDINI, F.; LASAGNI, A. Intangible assets and firm heterogeneity: Evidence from Italy. Research Policy, v. 43, n. 1, p. 202-213, 2014.

AVELINO, B. C.; PINHEIRO, L. E. T.; LAMOUNIER, W. M. Evidenciação de ativos intangíveis: estudo empírico em companhias abertas. Revista de Contabilidade e Organizações (RCO), v. 6, n. 14, p. 22-45, 2012.

AXTLE-ORTIZ, M. A. Perceiving the value of intangible assets in context. Journal of Business Research, v. 66, n. 3, p. 417-424, 2013.

BARNEY, J. B. Firm resources and sustained competitive advantage. Journal of Management, v. 17, n. 1, p. 99-120, 1991.

BEUREN, I. M.; THEISS, V.; SANT’ANA, S. V. Conservadorismo Contábil no reconhecimento de Ativos Intangiveis: um estudo nas empresas da BM\&FBOVESPA. Contabilidade, Gestão e Governança, v. 16, n. 1, p. 98-111, 2013.

BOUJELBEN, S.; FEDHILA, H. The effects of intangible investments on future OCF. Journal of Intellectual Capital, v. 12, n. 4, p. 480-494, 2011.

BRITO, E. P. Z.; BRITO, L. A. L.; MORGANTI, F. Inovação e o desempenho empresarial: lucro ou crescimento? RAE Eletrônica, v. 8, n. 1, p. 45-59, 2009.

CABRAL, J. E. Determinantes da propensão para inovar e da intensidade inovativa em empresas da indústria de alimentos do Brasil. RAC - Revista de Administração Contemporânea, v. 11, n. 4, p. 87-108, out./dez., 2007.

CABRAL, J. E.; TRAILL, W. B. (2003). Technological innovation profile in the Brazilian food industry. In: INTERNATIONAL CONFERENCE OF THE IBEROAMERICAN ACADEMY OF MANAGEMENT, 3., 2003, São Paulo. Proceedings... São Paulo: EAESP - FGV, 2003.

CAMPOS, B.; RUIZ, A. U. Padrões setoriais de inovação na indústria brasileira. Revista Brasileira de Inovação, v. 8, n. 1, p. 167-210, jan./jun. 2009.

CAVALCANTI, M.; PEREIRA, A.; NETO. Inovação tecnológica: há uma pedra no meio do caminho. Liinc em Revista, v. 10, n. 2, p. 726-741, 2014.

CHAN, L. K.; LAKONISHOK, J.; SOUGIANNIS, T. The stock market valuation of research and development expenditures. The Journal of Finance, v. 56, n. 6, p. 2431-2456, dec., 2001.

CHEN, J.; JIANG, C.; LIN, Y. What determine firms' capital structure in China?. Managerial Finance, v. 40, n. 10, p. 1024-1039, 2014.

CHO, H. J.; PUCIK, V. Relationship between innovativeness, quality, growth, profitability, and market value. Strategic Management Journal, v. 26, n. 6, p. 555-575, 2005. 
COCKBURN, I. I.; HENDERSON, R. M.; STERN, S. Untangling the origins of competitive advantage. Strategic Management Journal, v. 21 , n. $10-11$, p. $1123-1145,2000$

COCKBURN, I.; GRILICHES, Z. Industry effects and appropriability measures in the stock market's valuation of R\&D and patents. American Economic Review, v. 78, n. 2, p. 419-423, 1987.

COHEN, W. M.; LEVINTHAL, D. A. Innovation and learning: the two faces of R\&D. The Economic Journal, v. 99, n. 397, p. 569-596, 1989.

COMITÊ DE PRONUNCIAMENTOS CONTÁBEIS. Pronunciamento Técnico CPC 04 (R1) - Ativo intangivel, de 05 de novembro de 2010. Disponível em: <http://www.cpc.org.br/Arquivos/Documentos/187_CPC_04_R1_rev\%2006.pdf >. Acesso em: 15 jan. 2015.

CORRADO, C.; HULTEN, C.; SICHEL, D. Measuring capital in the new economy. National Bureau of Economic Research Studies in Income and Wealth: University of Chicago Press, 2005.

COSTA. T. A.; SILVA, A. H. C.; LAURENCEL, L. C. Escolha de práticas contábeis: um estudo sobre propriedades para investimento em empresas brasileiras não financeiras de capital aberto. Revista Contabilidade e Organizações - RCO, v. 7, n. 18, p. 26-36, 2013.

CRISÓSTOMO, V. L. Ativos Intangiveis: estudo comparativo dos critérios de reconhecimento, mensuração e evidenciação adotados no Brasil e em outros países. Revista Contabilidade, Gestão e Governança, v. 12, n. 1, p. 50-68, 2009.

DECKER, F; ENSSLIN, S. R.; REINA, D. R. M.; REINA, D. A relação entre os ativos intangíveis e a rentabilidade das empresas listadas no Índice BOVESPA. REUNA, v. 18, n. 4, p. 75-92, 2013.

DIAS FILHO, J. M.; CORRAR, L. J. Análise multivariada: para os cursos de administração, ciências contábeis e economia. São Paulo: Atlas, 2009.

ERNST\&YOUNG. US GAAP versus IFRS: the basics. .Net. 2011. Disponível em: <http://www.ey.com/Publication/vwLUAssets/ US_GAAP_v_IFRS:_The_Basics/\$FILE/US\%20GAAP\%20v\%20IFRS\%20Dec\%202011.pdf>. Acesso em 17 jan. 2015.

GOUVEIA, F. Inovação e patentes: o tempo de maturação no Brasil. Inovação Uniemp, v. 3, n. 3, p. 24-25, 2007.

GREENHALGH, C.; ROGERS, M. The value of innovation: the interaction of competition, R\&D and IP. Research Policy, v. 35, n. 4, p. 562-580, 2006.

GUJARATI, D. N.; PORTER, D. C. Econometria básica. 5. ed. Porto Alegre: AMGH, 2011.

HOLTHAUSEN, R. W.; WATTS, R. L. The relevance of the value-relevance literature for financial accounting standard setting. Journal of Accounting and Economics, v. 31, p. 3-75, 2001.

KAYO, E. K.; FAMÁ, R. A estrutura de Capital e o Risco das Empresas Tangível-intensivas e Intangível-intensivas. Revista de Administração da Universidade de São Paulo - RAUSP, v. 39, n. 2, p. 164-176, 2004.

KAYO, E. K.; TEH, C. C.; BASSO, L. F. C. Ativos intangíveis e estrutura de capital: a influência das marcas e patentes sobre o endividamento. Revista de Administração, v. 41, n. 2, p. 158-168, 2006.

LEDOUX, M. J.; CORMIER, D. Market assessment of intangibles and voluntary disclosure about innovation: the incidence of IFRS. Review of Accounting and Finance, v. 12, n. 3, p. 286-304, 2013.

LEV, B. Intangibles: management, measurement and reporting. Washington: Brookings Institution Press, 2001.

MACAGNAN, C. B. Evidenciação voluntária: fatores explicativos da extensão da informação sobre recursos intangíveis. Revista Contabilidade \& Finanças, v. 20, n. 50, p. 46-61, 2009.

MARROCU, E.; PACI, R.; PONTIS, M. Intangible capital and firm's productivity. Industrial and Corporate Change, v. 21, n. 2, p. 377-402, 2011.

MARTINS, G. A. Manual para elaboração de monografias e dissertações. 3. ed. São Paulo: Atlas, 2002.

MIRANDA, K. F; GALLON, A. V.; NOGUEIRA, L. C. B. Ativos intangíveis e grau de inovação: fatores influentes no desempenho econômico empresarial?. In: SIMPÓSIO DE ADMINISTRAÇÃO DA PRODUÇÃO - SIMPOI, 14., 2011, São Paulo. Anais... São Paulo: FGV-EASP, 2011. p. 1-17.

MONACO, R. Brasil ocupa penúltima posição em ranking de patentes válidas..Net, Brasília, abr. 2014. Disponível em: <http:// www.portaldaindustria.com.br/cni/imprensa/2014/04/1,35905/brasil-ocupa-penultima-posicao-em-ranking-de-patentes-validas. html>. Acesso em: 16 dez. 2014.

MOURA, G. D.; SCARPIN, J. E.; MECKING, D. V. Competitividade de mercado, ativos intangíveis e eficiência nos ativos fixos em companhias abertas na BM\&FBovespa. Revista Enfoque, v. 32, n. 3, p. 19-35, 2013.

NISIYAMA, E. K.; OYADOMARI, J. C. T. A busca da inovação e a cadeia de valores. Revista de Administração da Unimep, v. 10, n. 1, p. 189-214, 2012.

PAVITT, K. Sectoral patterns of technical change: towards a taxonomy and a theory. Research Policy, v. 13, p. 343-73, 1984. 
PEREZ, M. M.; FAMÁ, M. Ativos intangíveis e o desempenho empresarial. Revista contabilidade e finanças, v. 17, n. 40, p. $7-24,2006$.

PUCCI, S.; CENCI, M.; TUTINO, M.; LULY, R. Intangible assets: current requirements, social statements, integrated reporting, and new models. In: RUSS, M. (Ed.). Value Creation, reporting, and signaling for human capital and human assets. New York: Palgrave Macmillan, 2014. p. 179-211.

REINA, D.; ENSSLIN, S. R.; JORGE, K. P. Reconhecimento e gerenciamento do valor da marca empresarial: investigação junto às empresas pertencentes ao setor de governança corporativa da BM\&FBovespa. Revista Gestão Organizacional (RGO), v. 3, n. 1, p. 27-43, 2010.

RITTA, C. O.; ENSSLIN, S. R. Investigação sobre a relação entre ativos intangíveis e variáveis financeiras: um estudo nas empresas brasileiras pertencentes ao Índice IBovespa nos anos de 2007 e 2008. In: CONGRESSO USP DE CONTROLADORIA E CONTABILIDADE, 10., 2010, São Paulo. Anais... São Paulo: USP, 2010. p. 1-16.

RITTA, C.O.; ENSSLIN, S.R.; RONCHI, S. H. A evidenciação dos ativos intangíveis nas empresas brasileiras: empresas que apresentaram informações financeiras à bolsa de valores de São Paulo e Nova York em 2006 e 2007. Revista Eletrônica de Ciência Administrativa, v. 9, n. 1, p. 62-75, 2010.

SÁNCHEZ, P.; CHAMINADE, C.; OLEA, M. Management of intangibles - An attempt to build a theory. Journal of Intellectual Capital, v. 1, n. 4, p. 312-327, 2000.

SANDNER, P. G.; BLOCK, J. The market value of R\&D, patents, and trademarks. Research Policy, v. 40, n. 7, p. 969-985, set., 2011.

SCHUMPETER, J. A. Teoria do desenvolvimento econômico: uma investigação sobre lucros, capital, crédito, juro e o ciclo econômico. 3. ed. São Paulo: Nova Cultural, 1988.

SHAKINA, E.; MOLODCHIK, M. Intangible-driven value creation: supporting and obstructing factors. Measuring Business Excellence, v. 18 , n. 3, p. 87-100, 2014

SORESCU, A.; SPANJOL, J. Innovation's effect on firm value and risk: insights from consumer packaged goods. Journal of Marketing, v. 72, p. 114-132, 2008.

TEECE, D. J. Intangible Assets and a Theory of Heterogeneous Firms. In: BOUNFOUR, A.; MIYAGAWA, T. (Eds.). Intangibles, market failure and innovation performance. Cham: Springer International Publishing, 2015. p. 217-239.

WATTS, R. L. Conservatism in accounting part I: explanations and implications. Accounting Horizons, v. 17, n. 3, p. 201-221, sept., 2003. 